\title{
The assembly of microtubule protein in vitro
}

\author{
The kinetic role in microtubule elongation of oligomeric fragments containing microtubule-associated \\ proteins
}

\author{
Peter M. BAYLEY,* Felicity M. M. BUTLER, David C. CLARK, Edward J. MANSER and \\ Stephen R. MARTIN \\ Division of Physical Biochemistry, National Institute for Medical Research, Mill Hill, London NW7 IAA, U.K.
}

(Received 12 September 1984/Accepted 20 December 1984)

\begin{abstract}
The kinetics of assembly were studied for bovine and pig microtubule protein in vitro over a range of conditions of $\mathrm{pH}$, temperature, nucleotide and protein concentration. The kinetics are in general biphasic with two major processes of similar amplitude but separated in rate by one order of magnitude. Rates and amplitudes are complex functions of solution conditions. The rates of the fast phase and the slow phase attain limiting values as a function of increasing protein concentration, and are more stringently limited at $\mathrm{pH} 6.5$ than $\mathrm{pH}$ 6.95. Such behaviour indicates that mechanisms other than the condensation polymerization of tubulin dimer become rate-limiting at higher protein concentration. The constancy of the wavelength-dependence of light-scattering and ultrastructural criteria indicate that microtubules of normal morphology are formed in both phases of the assembly process. Electrophoretic analysis of assembling microtubule protein shows that MAP- (microtubuleassociated-protein-)rich microtubules are formed during the fast phase. The rate of dissociation of oligomeric species on dilution of microtubule protein closely parallels the fast-phase rate in magnitude and temperature-dependence. We propose that the rate of this process constitutes an upper limit to the rate of the fast phase of assembly. The kinetics of redistribution of MAPs from MAP-rich microtubules may be a factor limiting the slow-phase rate. A working model is derived for the self-assembly of microtubule protein incorporating the dissociation and redistribution mechanisms that impose upper limits to the rates of assembly attainable by bimolecular addition reactions. Key roles are assigned to MAP-containing fragments in both phases of microtubule elongation. Variations in kinetic behaviour with solution conditions are inferred to derive from the nature and properties of fragments formed from oligomeric species after the rapid temperature jump. The model accounts for the limiting rate behaviour and indicates experimental criteria to be applied in evaluating the relative contributions of alternative pathways.
\end{abstract}

The mechanism of assembly of microtubules in vitro has been studied intensively (for reviews see Kirschner, 1978; Scheele \& Borisy, 1979; Timasheff \& Grisham, 1980). For assembly of microtubules from purified tubulin either alone (Carlier \& Pantaloni, 1978; Timasheff, 1981) or seeded by the addition of a small amount of sheared micro-

Abbreviations used: MT-protein, microtubule protein; MAPs, microtubule associated proteins; MgPCT, $\mathrm{Mg}^{2+}$-phosphocellulose-purified tubulin dimer.

* To whom correspondence should be addressed. tubules (Johnson \& Borisy, 1977) the mechanism of elongation is consistent with the addition of tubulin dimer to a growing polymer according to the polymeric condensation model proposed by Oosawa \& Asakura (1975).

Many studies of the physical characteristics and assembly properties of this system are, however, conducted with different starting material, namely microtubule protein (MT-protein), which is the product of repeated cycles of assembly and disassembly of microtubules. This material prepared from bovine or pig brain contains tubulin 
dimer of $M_{\mathrm{r}} 100000$ (Ponstingl et al., 1981 ; Krauhs et al., 1981) together with microtubule-associated proteins (MAPs), i.e. high- $M_{\mathrm{r}}$ components of $M_{\mathrm{r}}$ 350000 and 270000 (MAP1 and MAP2), and the tau group of proteins of $M_{\mathrm{r}} 50000-70000$. The relative proportions of tubulin and various MAPs in a given preparation of MT-protein depend on the source and preparative conditions (Scheele \& Borisy, 1979).

Solutions of MT-protein contain tubulin dimer and oligomeric complexes of tubulin plus MAPs, the major component being characterized as the species with $s_{20, \mathrm{w}}^{0}=30 \mathrm{~S}\left(M_{\mathrm{r}} 4 \times 10^{6}-5 \times 10^{6}\right)$ in both pig MT-protein (Marcum \& Borisy, 1978; Scheele \& Borisy, 1979) and bovine MT-protein (Bayley et al., 1982). In considering the selfassembly of MT-protein (as opposed to tubulin dimer), a central question is therefore the behaviour of these oligomeric species. In previous studies of the conformation, stability and interrelationship of the oligomeric species, it has been shown by c.d. (Clark et al., 1981; Martin et al., 1982), ultracentrifugation (Bayley et al., 1982), gel-filtration chromatography (Barton \& Riazi, 1982) and quasielastic light-scattering (Palmer et al., 1982) that the integrity of the $30 \mathrm{~S}$ species in bovine MT-protein is strongly dependent on solution conditions. These include temperature, ionic composition and, most importantly, $\mathrm{pH}$ over a narrow range from $\mathrm{pH} 6.0$ to $\mathrm{pH}$ 7.0. Under $\mathrm{pH} 6.5$ conditions, frequently used for assembly studies, the $30 \mathrm{~S}$ species is relatively stable and does not readily dissociate to its component tubulin plus MAPs. We have therefore now investigated the involvement of oligomeric species in both nucleation and elongation phases of assembly of MT-protein, by analysis of the kinetics of assembly under conditions known to affect the oligomeric composition. In addition, we have examined the product of assembly as a function of time, using electrophoretic analysis to quantify the proportions of MAP1, MAP2 and tubulin in the polymer, the wavelength-dependence of scattered light (cf. Correia \& Williams, 1983) and electron-microscopic characterization of the assembled microtubules.

In this work we have used a turbidimetric assessment of assembly. It has previously been shown that turbidity is proportional to the mass of microtubules formed from MT-protein (Gaskin et al., 1974), and the major contribution to turbidity in the elongation phase is from growing microtubules. Compared with X-ray scattering (Mandelkow et al., 1984a), light-scattering methods in general lack angular resolution, although quasielastic light-scattering is potentially capable of providing some resolved low-angle information (Palmer et al., 1982). The turbidimetric method has major practical advantages of experimental simplicity and applicability over a wide range of protein concentration, down to 10 -fold less than values used in time resolved X-ray work. Thus the two approaches are essentially independent and our findings are therefore complementary to the recent X-ray results (Mandelkow et al., 1980, 1982, $1983 a, b$; Bordas et al., 1983).

Barton \& Riazi (1980) reported that bovine MTprotein shows biphasic assembly kinetics. This phenomenon is dependent on solution conditions, notably pH (Bayley et al., 1983), and in both phases the rates become independent of protein concentration (Clark et al., 1984). We present here the quantification of these observations. The kinetic analysis indicates that the rate-determining steps in the multi-phase elongation process at concentrations greater than $1 \mathrm{mg} / \mathrm{ml}$ involve dissociation or isomerization of oligomers rather than being determined by the kinetics of bimolecular associations. We conclude that, in addition to the Oosawa condensation mechanism of tubulin dimer addition, the general mechanism for the assembly of MT-protein must include pathways in which certain oligomeric species are indeed involved in the elongation of the growing microtubule.

A working model of microtubule assembly is proposed that appears able to rationalize much of the extensive literature on MT-protein assembly in vitro. It accounts for the rate-limiting behaviour in both fast and slow phases, and includes explicitly a function for MAP-containing fragments in terms of the distribution and proportions of MAPs in the growing microtubule.

\section{Materials and methods}

\section{$M T$-protein preparations}

MT-protein was prepared from bovine brain by two cycles of assembly and disassembly in Mes buffer, $\mathrm{pH} 6.5$, in the presence of glycerol by a modification of the method of Shelanski et al. (1973) (see Clark et al., 1981). Before each experiment the stored MT-protein solution was taken through a further cycle of assembly, resuspended in the appropriate buffer and clarified by centrifugation at $4^{\circ} \mathrm{C}$. Pig MT-protein was prepared in the absence of glycerol by the method of Borisy et al. (1975).

Tubulin dimer was prepared by chromatography of bovine MT-protein over phosphocellulose that had been treated with $\mathbf{M g}^{2+}$ (Williams \& Detrich, 1979; Clark et al., 1981). The run buffer was $25 \mathrm{~mm}$ Mes containing $0.5 \mathrm{~mm}-\mathrm{MgCl}_{2}, 0.1 \mathrm{~mm}-\mathrm{EGTA}$, $1 \mathrm{M}$-glycerol and $1 \mathrm{~mm}$-2-mercaptoethanol, final pH 6.5. Peak fractions were dialysed into tubulin dimer reassembly buffer $(50 \mathrm{mM}$-Mes containing $7 \mathrm{mM}-\mathrm{MgCl}_{2}, 0.1 \mathrm{mM}-\mathrm{EGTA}, 3.4 \mathrm{M}$-glycerol and $1 \mathrm{~mm}$-2-mercaptoethanol, final pH 6.5) and stored at 
$-70^{\circ} \mathrm{C}$. Before an experiment a suitable portion of tubulin dimer preparation was thawed, assembled and pelleted, then resuspended in standard buffer ( $0.1 \mathrm{M}$-Mes containing $0.5 \mathrm{mM}-\mathrm{MgCl}_{2}$ and $0.1 \mathrm{~mm}$ EGTA, final pH6.5) containing $1 \mathrm{M}$-glycerol and clarified by centrifugation $(55000 \mathrm{~g}$ for $30 \mathrm{~min}$ at $\left.4^{\circ} \mathrm{C}\right)$. Whole MAP fraction was prepared by a procedure employing a heat-treatment step based on the method of Sandoval \& Weber (1980) as described previously (Woody et al., 1983). Ring fraction was obtained by chromatography of freshly cycled bovine MT-protein over Sepharose 6B as described by Erickson (1974). All preparations were characterized by polyacrylamide-gel electrophoresis in the presence of sodium dodecyl sulphate as described previously (Clark et al., 1981).

All reconstitution experiments involving the use of ring fraction, tubulin dimer and MAP fraction were performed in standard buffer containing $1 \mathrm{M}$-glycerol as a stabilizing agent. The results from these experiments were compared with the assembly of MT-protein in the same buffer.

\section{Assembly studies: kinetics}

In general the sample of MT-protein was prepared by dilution from stock solution (6$8 \mathrm{mg} / \mathrm{ml}$ ) in standard buffer at $10^{\circ} \mathrm{C}$ before the addition of nucleotide: when MT-protein was stored at $10^{\circ} \mathrm{C}$ at $1 \mathrm{mg} / \mathrm{ml}$ the lag phase lengthened and the fast-phase amplitude decreased, paralleling the well-known progressive loss of assembly competence with time. For assembly, MT-protein (typically at $1 \mathrm{mg} / \mathrm{ml}$ ) in standard buffer and with $1 \mathrm{mM}-\mathrm{GTP}$ was contained in a jacketed cuvette of path length $1 \mathrm{~cm}$ or $5 \mathrm{~mm}$. The temperature was raised rapidly $\left(t_{t} 12 \mathrm{~s}\right)$ from $10^{\circ} \mathrm{C}$ to an elevated temperature $\left(30,37\right.$ or $\left.42^{\circ} \mathrm{C}\right)$, and the assembly was followed by turbidity measurement at $330 \mathrm{~nm}$ with the Cary 118 spectrophotometer. The progress curve was recorded (from the initiation of the temperature jump) by on-line analogue-to-digital conversion into a PDP 11/23 computer, with data averaging to give an effective acquisition time of $4 \mathrm{~s}$ per point, and an overall scan time of 800 $1000 \mathrm{~s}$. A typical curve is shown in Fig. $1(a)$ and comprises (a) a small but distinct initial dip in turbidity, (b) a minimum value, (c) acceleration, $(d)$ growth or elongation phase and $(e)$ the approach to the plateau value characterizing steady-state assembly. The semi-logarithmic plot (Fig. 1b) shows clear biphasic kinetics in the growth phase, with rate constants generally differing by one order of magnitude. The major portion of the curve, typically from $10 \%$ to $95 \%$ of total amplitude, may be fitted to a two-exponential equation such that the time-dependent signal $A_{(t)}$ is given by:

$$
A_{(t)}=A_{\alpha}-A_{1} \cdot \mathrm{e}^{-k_{o b s} \cdot t}-A_{2} \cdot \mathrm{e}^{-k_{o b s} 2 t}
$$

Non-linear least squares analysis provides values for the rate parameters, $k_{\text {obs.1 }}$ and $k_{\text {obs.2 }}$, plus values of $A_{\alpha}, A_{1}$ and $A_{2}$. Amplitudes are evaluated consistently by forming a semi-logarithmic plot of
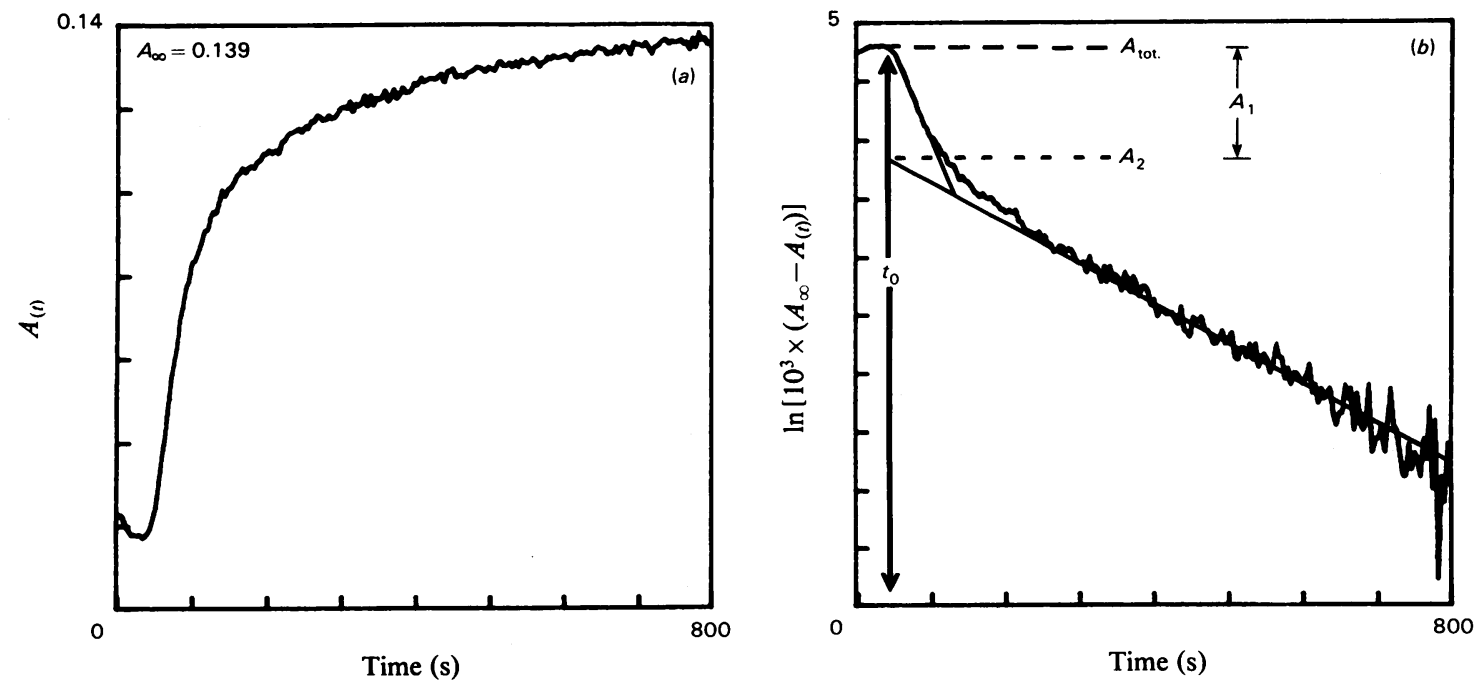

Fig. 1. Typical time course of assembly for bovine $M T$-protein at $0.8 \mathrm{mg} / \mathrm{ml}$ in standard bufjer containing ImM-GTP, at pH6.50 and $37^{\circ} \mathrm{C}$

(a) Direct plot showing the plateau value $A_{\infty}$. (b) Computed semi-logarithmic plot, showing fast and slow phases of assembly and the definition of $t_{0}$; the fitted curves fall within the noise level of the experimental curve. For details of the analysis, see the Materials and methods section. 
$\ln \left(A_{\alpha}-A_{(t)}\right)$ versus time, in which the origin $t_{0}$ is the time at which $A_{(t)}$ is minimum and amplitudes $A_{1}$ (fast) and $A_{2}$ (slow phase) are obtained by extrapolation (see Fig. 1). It may be noted that omission of the initial (fast-phase) data, or incomplete data collection at longer times, can yield an erroneous impression of single-phase kinetics.

\section{Assembly studies: analysis of assembled material}

The time course of assembly was followed analytically by using polyacrylamide-gel electrophoresis and electron microscopy to monitor the composition and morphology of the assembled material. MT-protein from storage was cycled a third time as described above, and the microtubules were harvested at $37^{\circ} \mathrm{C}$, being resuspended in cold buffer for $30 \mathrm{~min}$ and the MT-protein solution being stringently clarified by spinning for $40 \mathrm{~min}$ at $40000 \mathrm{rev} . / \mathrm{min}(100000 \mathrm{~g})$ at $4^{\circ} \mathrm{C}$ in the Beckman $\mathrm{L} 8$ centrifuge (type 50 rotor). A sample $(175 \mu \mathrm{l})$ of this microtubule protein $(3 \mathrm{mg} / \mathrm{ml})$ in standard buffer containing $1 \mathrm{mM}-\mathrm{GTP}$ at $5^{\circ} \mathrm{C}$, was placed in the A100 rotor of the Beckman Airfuge, pre-warmed at $35^{\circ} \mathrm{C}$, incubated for a given time, then spun at $95000 \mathrm{rev} . / \mathrm{min}(149000 \mathrm{~g})$ for $4 \mathrm{~min}$. The exact time at assembly temperature includes this incubation time plus a small fraction of the centrifugation time. The supernatant $(100 \mu \mathrm{l})$ was removed and the pellet, cooled to $0^{\circ} \mathrm{C}$, was resuspended in electrophoresis sample buffer to a known total volume before analysis of a sample by polyacrylamide-gel electrophoresis as above (with replacement of sodium dodecyl sulphate by $6 \mathrm{M}$ urea in separating and stacking gels). The bands, stained with Coomassie Brilliant Blue $R$, were quantified by densitometry, and the ratio of areas corresponding to the components (MAP1 + MAP2) and tubulin $(\alpha+\beta)$ was calculated.

Samples for electron microscopy were either prepared from pellet and supernatant as above, or taken directly from the assembling MT-protein solution at known times, by absorption on carboncoated copper grids, washed briefly with standard buffer (at 25 or $37^{\circ} \mathrm{C}$ ) and prepared both with and without fixation by glutaraldehyde, followed by negative staining with uranyl acetate for examination with the Philips 301 electron microscope.

\section{Wavelength-dependence of scattered light}

MT-protein $(3 \mathrm{mg} / \mathrm{ml})$ at $5^{\circ} \mathrm{C}$ in standard buffer containing $1 \mathrm{mM}-\mathrm{GTP}$ was placed in a $1 \mathrm{~cm}$ semimicro cell at $30^{\circ} \mathrm{C}$ in the Cary 118 spectrophotometer, with a blank cell containing buffer as reference. At defined starting times $\left(t_{i}\right)$, the sample was scanned rapidly over the range 360 to $330 \mathrm{~nm}$ at $1.0 \mathrm{~nm} / \mathrm{s}$ with $1 \mathrm{~s}$ time constant, and the turbidity (apparent absorption at wavelength $\lambda, A_{\lambda}$ ) was digitized directly on the PDP11/23 computer. The set of data for a given time $t_{\mathrm{i}}$ was corrected by interpolation to allow for the finite time of the scan, and the data were plotted at $2 \mathrm{~nm}$ intervals to give the value of the parameter $n$ in the expression:

$$
\log A_{\lambda}=-n \cdot \log \lambda+c
$$

\section{$M T$-protein dissociation kinetics}

A small volume of MT-protein $(10 \mathrm{mg} / \mathrm{ml})$ at $20^{\circ} \mathrm{C}$ was added to 9 vol. of buffer containing $1 \mathrm{mM}-$ GDP, preincubated at the desired temperature, in a $1 \mathrm{~cm}$ semi-micro cell and turbidity was monitored at $330 \mathrm{~nm}$, with data processing as above.

\section{Results \\ Assembly kinetics}

The biphasic assembly of microtubule protein was studied over the $\mathrm{pH}$ range 6.1-7.2 in standard Mes buffer at $37^{\circ} \mathrm{C}$, and the results are shown in Table 1 for extensive repeated experiments, yielding mean values and standard deviations. $k_{\text {obs.1 }}$ and $k_{\text {obs.2 }}$ show a monotonic increase with increasing $\mathrm{pH}$, in parallel with a progressive decrease of the total amplitude. The parameter

Table 1. $\mathrm{pH}$ variation of assembly kinetics for bovine $M T$-protein in standard buffer $\left(0.1 \mathrm{M}-\mathrm{Mes} / 0.5 \mathrm{mM}-\mathrm{Mg} \mathrm{g}^{2+} / 0.1 \mathrm{mM}-\mathrm{EGTA}\right)$ containing $1 \mathrm{mM}-G T P$ after temperature jump from $15^{\circ} \mathrm{C}$ to the indicated temperature, $T$

$n$ is the number of determinations giving mean and standard deviation as shown. All experiments were performed at protein concentration $0.85-0.95 \mathrm{mg} / \mathrm{ml}$ and $1 \mathrm{~cm}$ pathlength. Amplitudes (total $A_{\text {tot. }} ;$ slow phase $A_{2}$ ) are normalized to $1.0 \mathrm{mg} / \mathrm{ml} . \% \mathrm{SL}$ is the relative amplitude of slow phase. $k_{\text {init. }}$ is the initial slope calculated from the fitted parameters $k_{\text {obs.1 }}, k_{\text {obs.2 }}$ and normalized amplitudes $A_{1}$ and $A_{2}$, in absorbance units $/ \mathrm{min}$.

\begin{tabular}{lcccccccc}
$\mathrm{pH}$ & $T\left({ }^{\circ} \mathrm{C}\right)$ & $n$ & $10^{3} \times k_{\text {obs. } 1}$ & $10^{3} \times k_{\text {obs. }}$ & $A_{\text {tot. }}$ & $A_{2}$ & $\% \mathrm{SL}$ & $k_{\text {init. }}$ \\
\hline 6.1 & 37 & 10 & $19.5(1.2)$ & $1.61(0.04)$ & $0.191(0.023)$ & $0.079(0.015)$ & 41 & 0.132 \\
6.5 & 37 & 25 & $31.7(5.9)$ & $3.56(0.70)$ & $0.157(0.021)$ & $0.065(0.014)$ & 41 & 0.175 \\
6.95 & 37 & 16 & $44.6(6.3)$ & $5.14(1.23)$ & $0.137(0.013)$ & $0.084(0.008)$ & 61 & 0.152 \\
7.2 & 37 & 22 & $43.2(8.0)$ & $6.21(1.74)$ & $0.135(0.024)$ & $0.083(0.016)$ & 61 & 0.146 \\
6.5 & 30 & 14 & $11.5(1.4)$ & $1.68(0.069)$ & $0.127(0.016)$ & $0.045(0.007)$ & 35 & 0.059 \\
6.95 & 30 & 7 & $15.9(1.8)$ & $3.0(0.59)$ & $0.134(0.014)$ & $0.072(0.004)$ & 53 & 0.069
\end{tabular}


$k_{\text {init. }}$ (the initial rate of assembly) is obtained from progress curves simulated by using the kinetic parameters (Table 1), and differentiated numerically to give the slope at time zero. This parameter is a function of $k_{\text {obs. } 1}, k_{\text {obs. } 2}, A_{1}$, and $A_{2}$ and shows a maximum in the range pH6.5-6.9 (cf. Fig. 2). These results may be compared with the reported 'optimal $\mathrm{pH}$ ' for assembly; such a value, in addition to being dependent on the assay of assembly (e.g. viscosity; Olmsted \& Borisy, 1975), will also be a function of solution conditions and whether amplitude or rate $\left(k_{\text {init. }}\right)$ is used to assess assembly efficiency. The most noteworthy result is the progressive decrease in $A_{1}$ with increasing $\mathrm{pH}$ under conditions where the stability of $30 \mathrm{~S}$ oligomers decreases monotonically (Bayley et al., 1982).

Assembly at $30^{\circ} \mathrm{C}$ (Table 1) is also clearly biphasic; the relative rates are similar to those at $37^{\circ} \mathrm{C}$; a somewhat greater proportion of the amplitude is observed in the fast phase than at $37^{\circ} \mathrm{C}$. Thus the amplitude of the fast phase is favoured by lower temperature and by the lower $\mathrm{pH}$ values 6.5 and 6.1 , but is still clearly resolvable under all conditions.

In Table 2 are shown the assembly data for a number of cases of interest, as follows.

(i) In the presence of $1 \mathrm{M}$-glycerol (frequently used as a stabilizer of tubulin dimer conformation), the kinetics for assembly of bovine MT-protein at pH6.5 remain biphasic, with $k_{\text {obs.1 }}$ slightly diminished, and $k_{\text {obs.2 }}$ more significantly decreased. This is consistent with the observation by Keates (1980) that assembly kinetics are affected only at very high glycerol concentrations, although his results treated the assembly as a single-phase process.

(ii) For bovine MT-protein in phosphate buffer with $95 \%{ }^{2} \mathrm{H}_{2} \mathrm{O}$, used for n.m.r. experiments (Woody et al., 1983), biphasic kinetics are observed. The presence of ${ }^{2} \mathrm{H}_{2} \mathrm{O}$ causes a $2-3$-fold
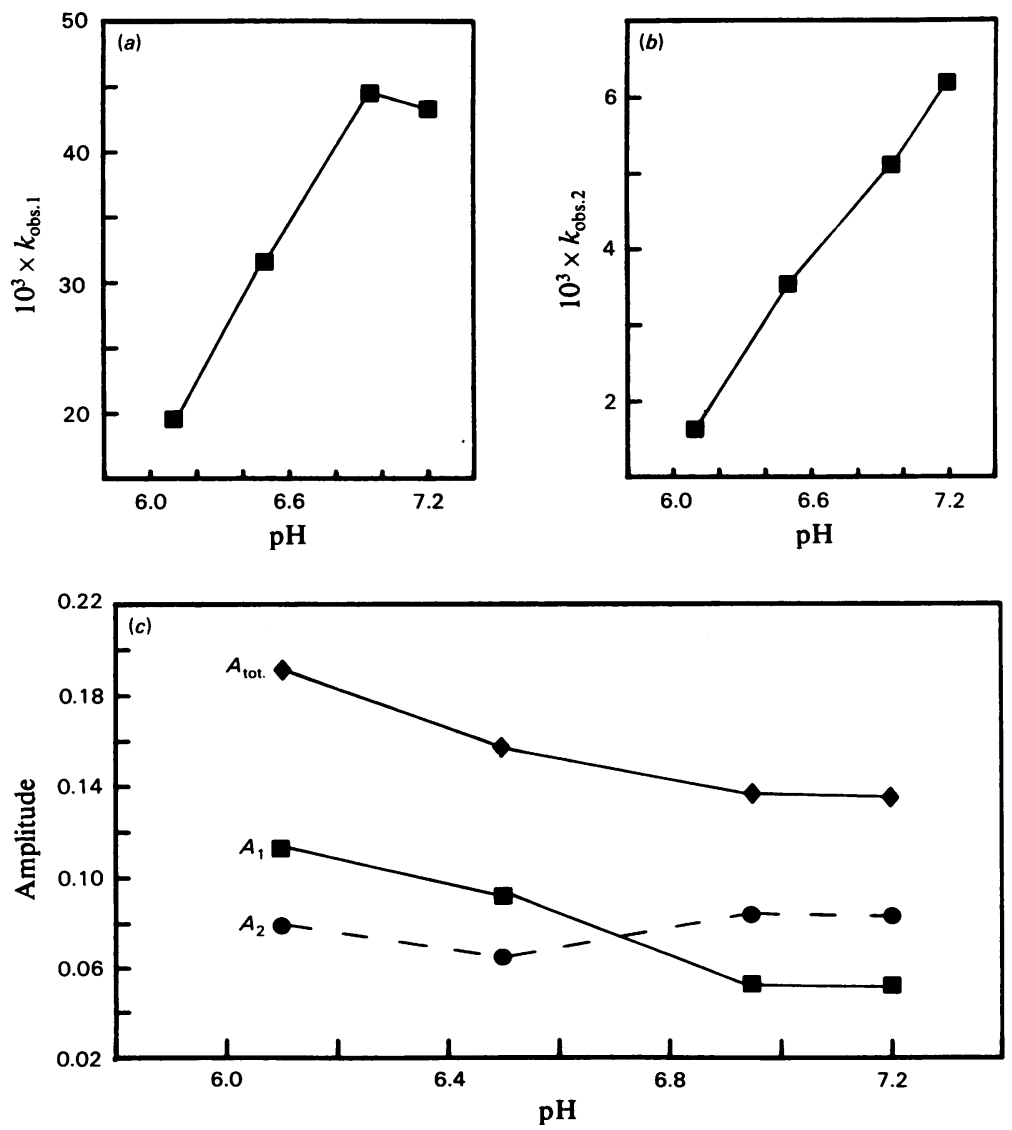

Fig. 2. Observed rate constants and reaction amplitudes as a function of $\mathrm{pH}$ for assembly of bovine $M T$-protein at $37^{\circ} \mathrm{C}$ in standard buffer containing I MM-GTP

Protein concentration is $1 \mathrm{mg} / \mathrm{ml}$. The kinetic parameters and experimental details are as defined in the text. (a) $k_{\text {obs. } 1}$; (b) $k_{\text {obs. } 2}$; (c) $A_{\text {tot. }}(\diamond), A_{1}(\square)$ and $A_{2}(\bigcirc)$. 
Table 2. Assembly kinetics for botine and pig MT-protein under different solution conditions, after temperature jump from $15^{\circ} \mathrm{C}$ to the indicated temperature, $\mathrm{T}$

Details are as in Table $1 . \% \mathrm{SL}=\left(\mathrm{A}_{2} / \mathrm{A}_{\text {tot. }}\right) \times 100$.

$\begin{array}{lllllllll}\text { Buffer } & \mathrm{pH} & T\left({ }^{\circ} \mathrm{C}\right) & n & 10^{3} \times k_{\text {obs. } 1} & 10^{3} \times k_{\text {obs. } 2} & A_{\text {tol. }} & A_{2} & \% \mathrm{SL}\end{array}$

\begin{tabular}{|c|c|c|c|c|c|c|c|c|}
\hline \multicolumn{9}{|l|}{ (a) Bovine MT-protein } \\
\hline $\begin{array}{c}0.1 \mathrm{M} \text {-Mes + } \\
1 \mathrm{M} \text {-glycerol }\end{array}$ & 6.5 & 37 & 5 & $25.0(2.8)$ & $1.17(0.23)$ & $0.132(0.011)$ & $0.075(0.007)$ & 57 \\
\hline $0.1 \mathrm{M}$-Phosphate in & $6.1^{*}$ & 37 & 4 & $7.2(0.5)$ & $0.64(0.24)$ & $0.154(0.002)$ & $0.065(0.004)$ & 42 \\
\hline${ }^{2} \mathrm{H}_{2} \mathrm{O}(95 \%)$ & $6.5^{*}$ & 37 & 4 & $4.6(0.7)$ & $0.50(0.18)$ & $0.100(0.005)$ & $0.043(0.005)$ & 43 \\
\hline \multirow[t]{2}{*}{$0.1 \mathrm{M}-\mathrm{Ph}$ osphate } & 6.1 & 37 & 4 & $20.2(0.6)$ & $1.67(0.25)$ & $0.090(0.019)$ & $0.050(0.012)$ & 56 \\
\hline & 6.5 & 37 & 4 & $16.1(6.4)$ & $1.85(0.34)$ & $0.085(0.011)$ & $0.045(0.006)$ & 53 \\
\hline $\begin{array}{l}0.1 \mathrm{M}-\mathrm{Mes}+ \\
0.1 \mathrm{M}-\mathrm{NaCl}\end{array}$ & 6.5 & 37 & 10 & $18.3(5.1)$ & {$[4.1,1.5,0.2]$} & 0.132 & 0.050 & $<38$ \\
\hline \multirow[t]{2}{*}{$0.1 \mathrm{M}$-Pipes } & 6.5 & 37 & 6 & $22.7(2.1)$ & $3.08(0.17)$ & $0.193(0.017)$ & $0.101(0.008)$ & 52 \\
\hline & 6.9 & 37 & 7 & N.D. $\dagger$ & $5.33(0.09)$ & $0.118(0.012)$ & $0.088(0.006)$ & $>75$ \\
\hline \multicolumn{9}{|l|}{ (b) Pig MT-protein } \\
\hline 0.1 м-Pipes & 6.94 & 37 & 4 & $57.0(6.8)$ & $3.0(0.10)$ & 0.103 & 0.055 & 53 \\
\hline $0.1 \mathrm{M}-\mathrm{Mes}$ & 6.5 & 37 & 2 & $22.8(2.9)$ & $1.75(0.05)$ & 0.206 & 0.075 & 36 \\
\hline
\end{tabular}

$\uparrow$ Not determined.

decrease in $k_{\text {obs. } 1}$ and $k_{\text {obs.2 }}$ (comparing pH 6.5 and pD6.1). In this buffer there appears to be a general decrease in the rates with increasing $\mathrm{pH}$ or $\mathrm{pD}$. In a different buffer system, Sato et al. (1982) have reported that $k_{\text {init. }}$ is enhanced and then inhibited by progressive increase in the mole fraction of ${ }^{2} \mathrm{H}, \mathrm{O}$.

(iii) The effect of including $0.1 \mathrm{M}-\mathrm{NaCl}$ in the assembly buffer showed that for several different protein preparations biphasic kinetics were consistently observed. In general the fast phase was approximately 2 -fold slower; the rates and amplitudes of slow phase were rather inconsistent.

(iv) Bovine MT-protein in Pipes buffer, $\mathrm{pH} 6.5$ or 6.95 (the buffer most frequently used with pig MT-protein), shows biphasic kinetics for assembly at $37^{\circ} \mathrm{C}$, with the fast phase more clearly resolved at $\mathrm{pH} 6.5$.

(v) Pig MT-protein in Pipes buffer, $\mathrm{pH} 6.95$, or Mes buffer, pH6.5, shows biphasic kinetics for assembly at $37^{\circ} \mathrm{C}$. Similar results are obtained for assembly at $30^{\circ} \mathrm{C}$ (results not shown). These results are in contrast with the single-phase kinetics reported by Johnson \& Borisy (1977) for pig MTprotein at $28^{\circ} \mathrm{C}$ and by Carlier (1983) for pig MTprotein at $30^{\circ} \mathrm{C}$.

\section{Protein-concentration-dependence of assembly kinetics}

The dependence of assembly kinetics on total protein concentration was examined for bovine MT-protein and for pig MT-protein under a variety of conditions ( $\mathrm{pH} 6.5-6.95)$ at assembly temperatures of 28.5 and $37^{\circ} \mathrm{C}$. The results are illustrated in Fig. 3. There is a relatively pronounced concentration-dependence at lower concentration $(<1.5 \mathrm{mg} / \mathrm{ml})$ only at $\mathrm{pH} 6.95\left(37^{\circ} \mathrm{C}\right)$, and both the rates become effectively independent of protein concentration above this value. At pH6.5 for assembly at 28.5 or $37^{\circ} \mathrm{C}$, both rates show independence of protein concentration from $1 \mathrm{mg} / \mathrm{ml}$ or less. The difference in behaviour at lower protein concentration at the two $\mathrm{pH}$ values is notable: greater re-equilibration of oligomeric material can occur at the higher $\mathrm{pH}$. Experiments performed for pig MT-protein at $37^{\circ} \mathrm{C}$ at $\mathrm{pH} 6.5$ (Mes) and at pH6.95 (Pipes) show biphasic kinetics throughout, with the rates either independent of protein concentration (pH6.95) or increasing only weakly with increasing protein concentration. In these experiments (Fig. 3) concentrations both of nuclei and adding species might be expected a priori to be functions of total protein concentration, leading to a relatively highorder dependence of observed rate on protein concentration. The existence of biphasic assembly kinetics under a wide range of experimental conditions indicates that the general mechanism of assembly is clearly more complex than the Oosawa model provides. Also, the fact that limiting rates are observed indicates that first-order rate-limiting processes are operating in both phases of assembly.

\section{Effect of $[G T P] /[G D P]$ ratios on assembly kinetics}

The effect of varying the [GTP]/[GDP] ratio at constant total nucleotide concentration ( $1 \mathrm{mM}$ ) was examined for standard buffer conditions at $37^{\circ} \mathrm{C}$. In contrast with a report by Dhalla et al. (1981), no effect was observed of the order of addition of reagents before the temperature-induced assembly. Fig. 4(a) shows that at pH6.5 there is a marked decrease in $k_{\text {obs.1 }}$ as a function of increasing [GDP], with rate decreased by half at $50 \%$ mole fraction of GDP. The value of $k_{\text {obs.2 }}$ remains 

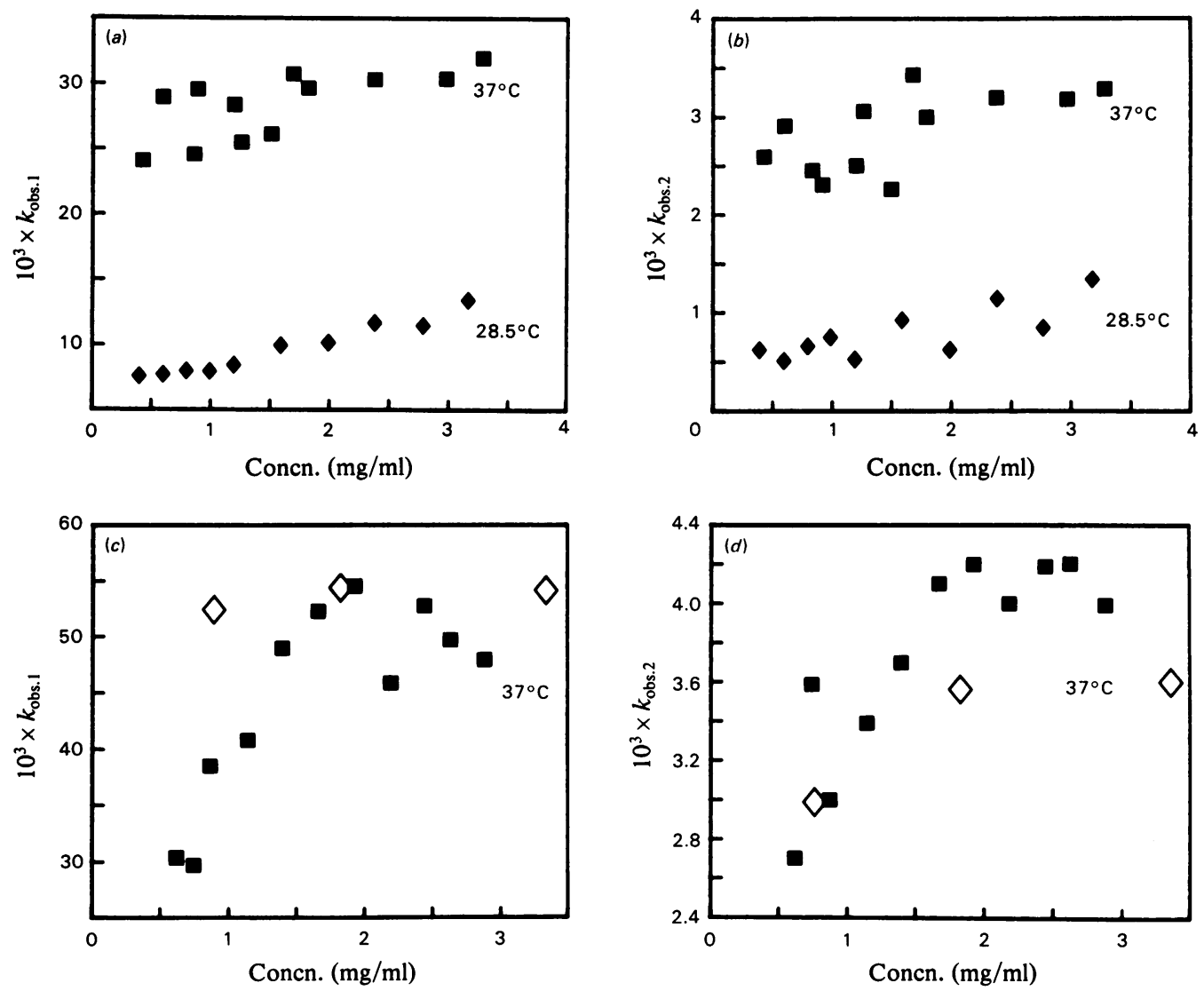

Fig. 3. Concentration-dependence for observed rate constants for assembly in standard buffer containing $1 \mathrm{mM}-G T P$ (a) $k_{\text {obs.1 }}$ for bovine MT-protein at $\mathrm{pH} 6.50$ and $37^{\circ} \mathrm{C}(\square)$ and at $28.5^{\circ} \mathrm{C}(\bullet)$. $(b) k_{\text {obs.2 }}$ for bovine MT-protein at pH 6.50 and $37^{\circ} \mathrm{C}(\square)$ and at $28.5^{\circ} \mathrm{C}(\diamond) .(c) k_{\text {obs.1 }}$ for bovine MT-protein $(\square)$ and for pig MT-protein $(\diamond)$, at pH6.95 and $37^{\circ} \mathrm{C} .(d) k_{\text {obs. } 2}$ for bovine MT-protein $(\square)$ and for pig MT-protein $(\diamond)$, at pH 6.95 and $37^{\circ} \mathrm{C}$.

constant. The total amplitude decreases to approx. $60 \%$ of the value with GTP alone, and there is a progressive increase in $A_{2}$ from $30 \%$ to $60 \%$. The fact that substantial assembly was observed in $1 \mathrm{mM}$-GDP (albeit effectively all slow phase) may reflect a small GTP content of the starting material, carried over from the pellet, estimated to be no greater than $40 \mu \mathrm{M}$. At pH7.2 (Fig. $4 b$ ), similar results are found with an increasing proportion of slow phase with rate $k_{\text {obs. } 2}$ remaining constant as a function of increasing mole fraction of GDP. In this case, no fast phase could be analysed beyond $28 \%$ mole fraction of GDP.

The presence of GDP at a substantial molar ratio decreases both the rate and amplitude of the fast phase. Slow-phase rates are not affected; and, although the total amplitude decreases relative to that in GTP alone, the amplitude of the slow phase appears to increase roughly in proportion to the decrease of the fast-phase amplitude.

\section{Assembly of reconstituted MT-protein mixtures}

Assembly was studied for bovine MT-protein preparations, recombined as mixtures of tubulin dimer and oligomeric material separated by gel filtration on Sepharose 6B (Erickson, 1974) and for mixtures of tubulin dimer plus whole MAP fraction (MAP2 plus tau) obtained by heat treatment of MT-protein (see the Materials and methods section). These experiments are performed with MAP-free tubulin dimer from phosphocellulose chromatography (MgPCT dimer), which is stabilized by $1 \mathrm{M}$-glycerol.

In the reconstitution experiments, dimer plus MAPs were preincubated at $10^{\circ} \mathrm{C}$ with standard buffer ( $\mathrm{pH}$ 6.5) containing $1 \mathrm{M}$-glycerol, before the addition of GTP, then assembled at $37^{\circ} \mathrm{C}$. No effect of preincubation time up to $15 \mathrm{~min}$ was observed in the parameters characterizing the biphasic assembly; similar results were obtained 

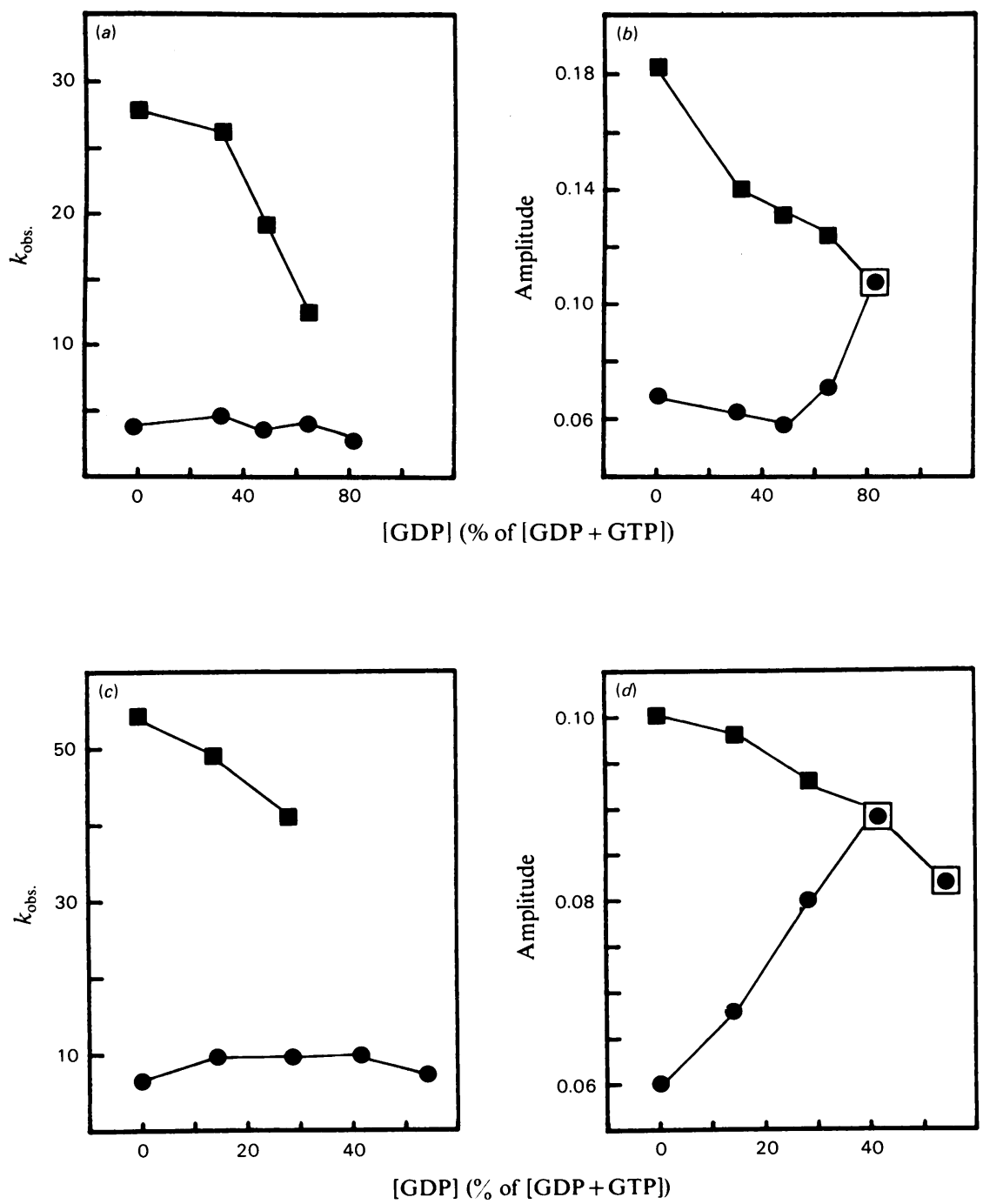

Fig. 4. Dependence of $k_{\text {obs. } 1}, k_{\text {obs.2 }}$, total amplitude $\left(A_{\text {to. }}\right)$ and slow-phase amplitude $\left(A_{2}\right)$ on $[G D P] /[G T P]$ ratio for assembly of bovine MT-protein at $1 \mathrm{mg} / \mathrm{ml}$ in standard buffer at $37^{\circ} \mathrm{C}$ in solutions containing a total nucleotide concentration of $1 \mathrm{mM}$

(a) $\mathrm{pH} 6.50 ; k_{\mathrm{obs} .1}(\square)$ and $k_{\mathrm{obs.2}}$ pH 7.20; $A_{\text {tot. }}(\square)$ and $A_{2}(O)$.

(b) $\mathrm{pH} 6.50 ; A_{\text {tot. }}(\square)$ and $A_{2}$

(c) $\mathrm{pH} 7.20 ; k_{\mathrm{obs} .1}$

and $k_{\text {obs.2 }}$

when the preincubation was performed in the order dimer plus GTP before addition of MAPs. A qualitative correlation was observed between fastphase amplitude and the amount of MAPs used. In recombining the oligomeric fraction (rings) with $\mathrm{MgPCT}$ dimer, a clearer quantification is obtained (Fig. 5): biphasic kinetics are observed throughout, and the rates $k_{\text {obs.1 }}$ and (to a lesser extent) $k_{\text {obs.2 }}$ are independent of the relative proportions of the components of the mixture employed. The total amplitude is a smooth function of the mole fraction of oligomer, and this is principally due to the fastphase amplitude being directly dependent on the amount of oligomeric component in the sample. Compared with the normal MT-protein preparation (approx. 50\% oligomer) the rates are consistent; the total amplitude attainable by $100 \%$ oligomer is, however, twice that found with MTprotein alone.

Events during lag phase: dissociation of oligomeric material

The initial event following the temperature increase to initiate assembly is a small but welldefined decrease in turbidity leading to the observed 'dip' during the brief lag phase. Experi- 

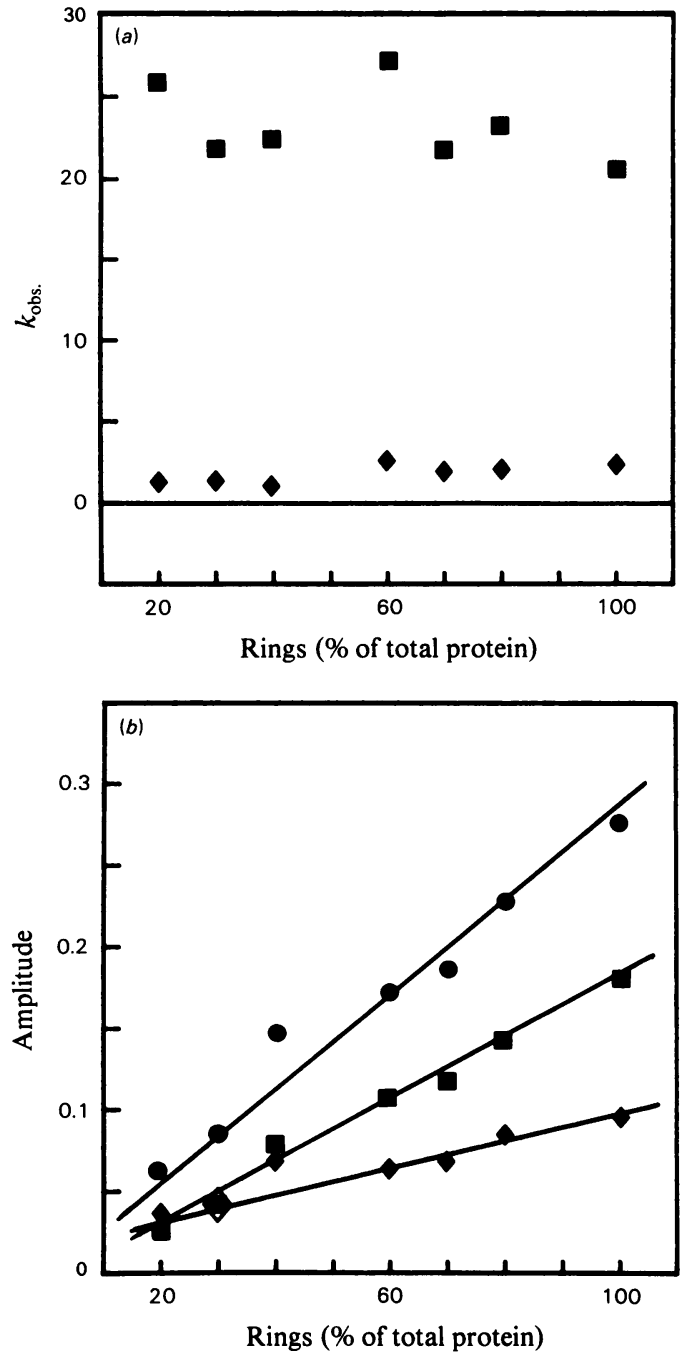

Fig. 5. Rate-constant and amplitude data for assembly of mixtures of Sepharose $6 B$ rings and $M g P C T$ dimer at $a$ total protein concentration of $1 \mathrm{mg} / \mathrm{ml}$ in standard buffer containing $1 \mathrm{M}-\mathrm{glycerol}$ and $1 \mathrm{mM}-\mathrm{GTP}\left(\mathrm{pH} 6.50,37^{\circ} \mathrm{C}\right)$

Experimental details are given in the text. (a) $k_{\text {obs.1 }}$

( $\square)$ and $k_{\text {obs. } 2}(\bullet)$. (b) $A_{\text {tot. }}(\bigcirc), A_{1}(\square)$ and $A_{2}(\bullet)$.

ments were performed to measure the rate of decrease of turbidity of MT-protein subjected to a 10 -fold dilution to $1 \mathrm{mg} / \mathrm{ml}$, at constant temperature under non-assembly conditions with buffers containing $1 \mathrm{~mm}-\mathrm{GDP}$. A typical trace is shown in Fig. 6(a). The amplitude of such dissociation events is relatively small and, like the rate, is temperature-dependent. Comparing these data with the temperature-dependence of assembly under similar conditions from 28 to $41^{\circ} \mathrm{C}$ with buffers containing $1 \mathrm{mM}-\mathrm{GTP}$, it is seen (Fig. 6b) that the rate of dissociation is closely similar
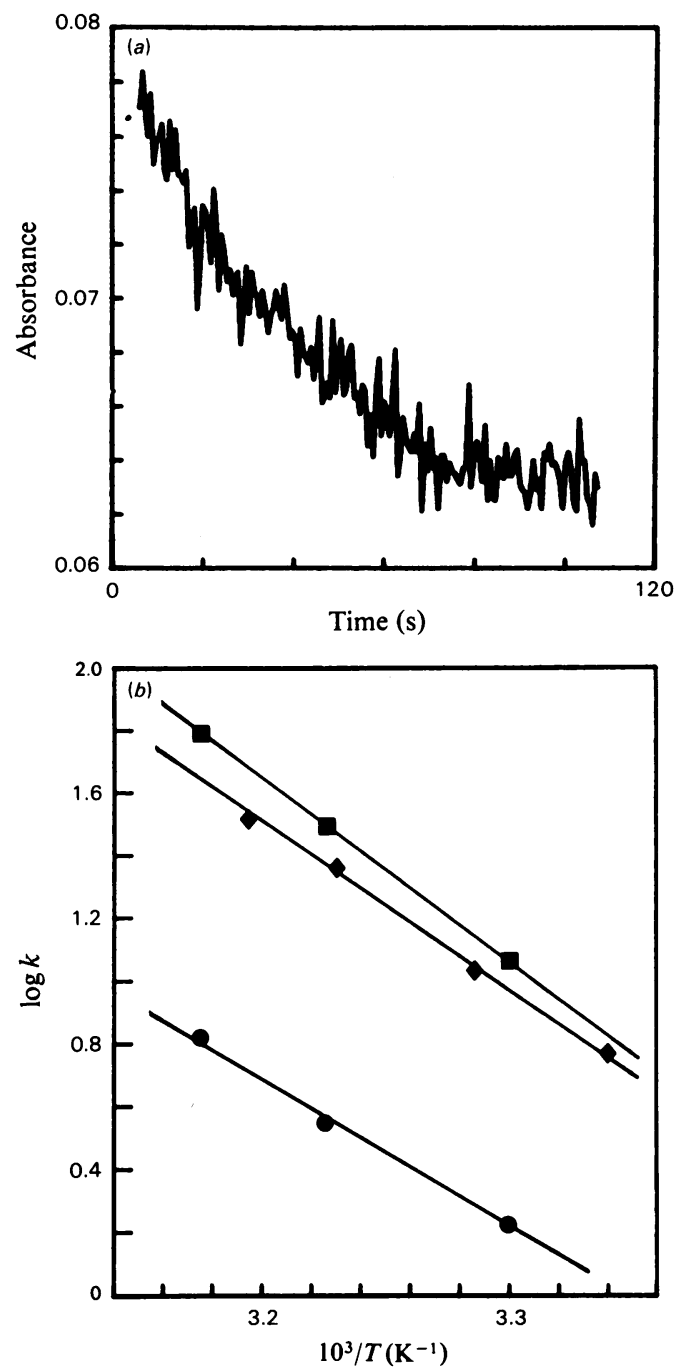

Fig. 6. (a) Absorbance as a function of time for bovine MTprotein undergoing dissociation after a 10-fold dilution to a concentration of $1 \mathrm{mg} / \mathrm{ml}$ in standard buffer at pH6.5 and $37^{\circ} \mathrm{C}$ in the presence of $1 \mathrm{mM}-\mathrm{GDP}$ and $(b)$ temperaturedependence of the observed rate constants for the assembly of bovine MT-protein in standard buffer at pH6.50 ( $k_{\text {obs. } 1}$ and $k_{\text {obs.2 }}$ ) and for dissociation as in (a)

In (a) analysis as a single exponential yields $k_{\text {diss. }}=0.0253 \mathrm{~s}^{-1}$. In $(b): \square, k_{\text {obs. } 1} ; \bigcirc, k_{\text {obs. } 2} ; \bullet$, $k_{\text {diss. }}$.

to the rate of the fast phase both in magnitude and temperature-dependence. The Arrhenius plot for the dissociation rate indicates activation parameters $\Delta H^{\ddagger}=107.6 \pm 11.7 \mathrm{~kJ} / \mathrm{mol}$ $(25.7 \pm 2.8 \mathrm{kcal} / \mathrm{mol})$ and $\Delta S^{\ddagger}=121.0 \pm 39.8 \mathrm{~kJ}$. $\mathrm{mol}^{-1} \cdot \mathrm{K}^{-1} \quad(28.9 \pm 9.5 \mathrm{e} . \mathrm{u}$.$) . The correspond-$ ing values for $k_{\text {obs. } 1}$ are $111.4 \pm 10.5 \mathrm{~kJ} / \mathrm{mol}$ $(26.6 \pm 2.5 \mathrm{kcal} / \mathrm{mol})$ and $135.2 \pm 30.6 \mathrm{~kJ}$. 
$\mathrm{mol}^{-1} \cdot \mathrm{K}^{-1}(32.3 \pm 7.3 \mathrm{e} . \mathrm{u}$.$) , those for k_{\text {obs. } 2}$ are $89.2 \pm 5.4 \mathrm{~kJ} / \mathrm{mol} \quad(21.3 \pm 1.3 \mathrm{kcal} / \mathrm{mol}) \quad$ and $44.8 \pm 13.0 \mathrm{~kJ} \cdot \mathrm{mol}^{-1} \cdot \mathrm{K}^{-1} \quad(10.7 \pm 3.1$ e.u. $)$. Thus both the oligomer dissociation reaction and the fast-phase assembly are entropy-driven processes.

\section{Investigation of the material formed during assembly}

Polyacrylamide-gel electrophoresis. In Fig. 7(a) the analysis of a typical assembly experiment is shown for the pellet and supernatant from ultracentrifugation at $149000 \mathrm{~g}$ of samples of threetimes-cycled MT-protein incubated for the times shown. The bands corresponding to MAPl and MAP2 are clearly associated preferentially with the pelletable material from the earliest times onwards, and are barely detectable in the supernatant of the sample incubated for longer than $60 \mathrm{~s}$. The quantitative results for a set of similar experiments (Table 3) show the initial formation of material with a high MAP/tubulin ratio, which progressively decreases towards the steady-state value, as determined in further assembly of the starting material under identical conditions. Initial enrichment of MAP2 in assembled microtubules was previously observed when bovine MT-protein (twice cycled in the absence of glycerol) was incubated for periods of $10-30 \mathrm{~s}$ before centrifugation at $39000 \mathrm{~g}$ for $15 \mathrm{~min}$ at $37^{\circ} \mathrm{C}$ and qualitative analysis by polyacrylamide-gel electrophoresis (Stearns \& Brown, 1979). Our results quantify the preferential incorporation of MAPs at an even earlier time of incubation under assembly conditions, and confirm the initial formation of MAP-rich microtubules.

Wavelength-dependence of light-scattering. In order to examine the possible formation of aberrant structures such as sheets of protofilaments and laterally associated microtubules, the parameter $n$ (the negative exponent of the wavelength-dependence of scattered light) was measured for a solution of MT-protein at $30^{\circ} \mathrm{C}$ as a function of time (see the Materials and methods section). The lower temperature and the limited wavelength range $(360$ to $330 \mathrm{~nm})$ were used to enhance time resolution. The mean value $(n=3.3)$ is consistent with normal microtubule formation, being close to that predicted theoretically for infinitely long thin rods $(n=3.0-3.2)$, and clearly different from the lower values found for more extended structures

Table 3. Protein composition of pelleted microtubules as a function of time after initiation of assembly at $35^{\circ} \mathrm{C}$ in standard buffer containing I MM-GTP

The ratios are assessed from measurement of stained polyacrylamide gels, as in Fig. 7. Experimental details are given in the text. Numbers of independent determinations from separate experiments are indicated in parentheses.

Incubation time

Ratio

(s)

$(\mathrm{MAP1}+\mathrm{MAP} 2) /$ tubulin

\begin{tabular}{cc}
\hline 30 & $0.35(5)$ \\
60 & $0.29(8)$ \\
90 & $0.26(1)$ \\
120 & $0.27(4)$ \\
300 & $0.26(5)$ \\
1200 & $0.24(3)$ \\
1800 & $0.25(2)$ \\
Control MT-protein & $0.24(2)$ \\
(4th cycle in & \\
standard buffer, & \\
no glycerol) &
\end{tabular}

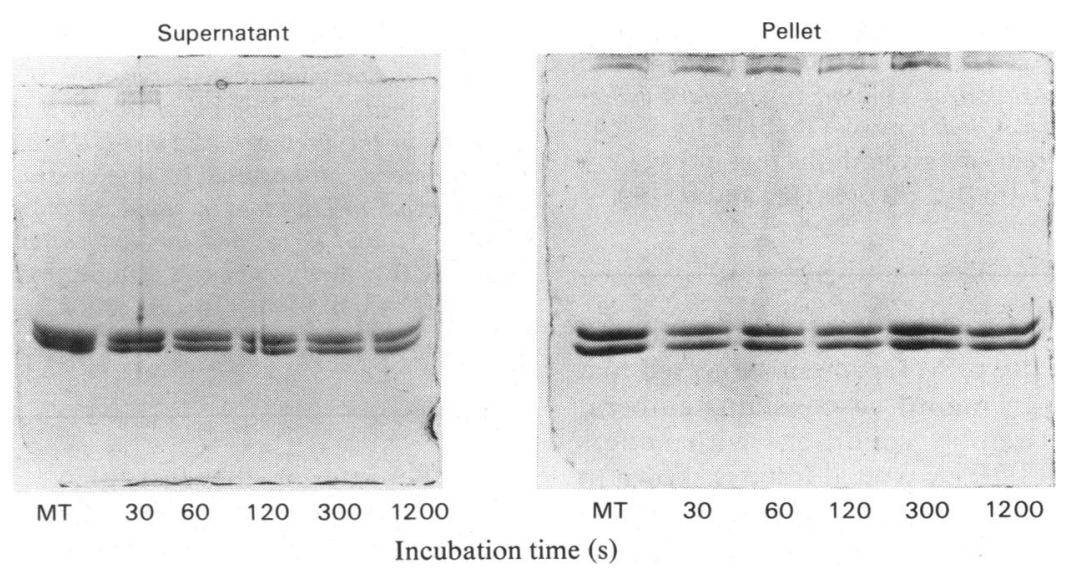

Fig. 7. Electrophoretic analysis of MT-protein assembly, showing the intense bands of tubulin $\alpha \beta$-heterodimer and weaker bands of $M A P I$ and $M A P 2$

Samples were incubated at $35^{\circ} \mathrm{C}$ for the time shown before Airfuge centrifugation (see the Materials and methods section). The changes in MAP1 and MAP2 indicate rapid incorporation of these proteins into pelletable microtubules. The track marked MT is the control MT-protein, incubated for $1200 \mathrm{~s}$. 
(see, e.g., Berne, 1974; Camerini-Otero \& Day, 1978; Correia \& Williams, 1983). Table 4 indicates that $n$ and hence the shape of the principal scattering species remains effectively constant throughout both phases of the assembly of MTprotein under these conditions.

Electron microscopy. Samples for electron microscopy were either absorbed from a solution of assembled MT-protein (being monitored by turbidity) or taken from the pellet and supernatant fractions from the Airfuge experiments (see the Materials and methods section). In all cases, and independent of whether the absorbed material was briefly fixed with glutaraldehyde, the polymeric material observed by negative staining is predominantly microtubules of normal morphology, showing 13-14 protofilaments. The rough-walled appearance (Fig. 8) indicates the presence of a substantial proportion of MAPs in the assembled microtubules, throughout the whole time range examined.

The products of assembly were examined for experimental conditions and protein concentrations in which the assembly kinetics are biphasic, and the rates of both fast and slow phases have achieved their plateau values. The results argue for the formation of normal microtubules from early times in the assembly process. We cannot exclude the possible presence of minor amounts of polymorphic forms, which have been observed, under other conditions, to form side branches of the assembly process (Mandelkow et

Table 4. Wavelength-dependence of scattered light during the assembly of $M T$-protein $(2.75 \mathrm{mg} / \mathrm{ml})$ at $30^{\circ} \mathrm{C}$ in Mes buffer, $\mathrm{pH} 6.5$

The wavelength range was $360-330 \mathrm{~nm}$; for details see the text. The progress of fast and slow phases was calculated with typical values of $k_{\text {obs. } 1}=1 \times 10^{-2} \mathrm{~s}^{-1}$ and $k_{\text {obs. } 2}=1.5 \times 10^{-3} \mathrm{~s}^{-1}$, and the time origin at $100 \mathrm{~s}$ for the start of assembly.

\begin{tabular}{crcc} 
& \multicolumn{2}{c}{$\%$ of phase } \\
\cline { 2 - 3 } $\begin{array}{c}\text { Time } \\
\text { (s) }\end{array}$ & Fast & Slow & $n$ \\
\hline 100 & 0 & 0 & - \\
150 & 40 & 7 & 2.93 \\
200 & 63 & 14 & 3.28 \\
250 & 78 & 20 & 3.28 \\
300 & 86 & 26 & 3.42 \\
350 & 92 & 31 & 3.44 \\
400 & 95 & 36 & 3.40 \\
500 & 98 & 45 & 3.32 \\
600 & 99 & 53 & 3.27 \\
700 & $>99$ & 59 & 3.27 \\
800 & $>99$ & 65 & 3.43 \\
900 & $>99$ & 70 & 3.32 \\
1000 & $>99$ & 74 & 3.40
\end{tabular}

al., 1983b). Occurrence of these forms often correlates with 'kinetic overshoot' phenomena (Mandelkow et al., 1982, 1983a; Detrich \& Wilson, 1983) and with structures giving excessive turbidity (Carlier \& Pantaloni, 1978; Correia \& Williams, 1983). Although $n$ is an insensitive parameter, its constancy over a wide time range also argues against the occurrence in slow phase of nonassembly processes such as the lateral association of assembled microtubules. Thus these three independent lines of evidence indicate that, for MTprotein under standard conditions, MAP-rich microtubules are formed from the earliest times of assembly, microtubules of normal morphology are produced continuously in assembly, and both the fast and the slow phases of assembly monitored by turbidity correspond to microtubule elongation.

\section{Discussion}

The use of turbidimetry as a quantitative assay of assembly of microtubules from MT-protein (Gaskin et al., 1974; Berne, 1974) has been substantiated by ultrastructural evidence of the normal morphology of the principal polymeric material identified throughout the assembly process. The wavelength-dependence of light-scattering, the absolute magnitude of the turbidity and the absence of 'kinetic overshoot phenomena' (Correia \& Williams, 1983) also argue against the formation of non-microtubule structures as the main product in assembly under these solution conditions. The kinetic observations are therefore interpreted as a quantitative measure of microtubule elongation.

The results reported in the present paper support the view that the general mechanism for the assembly of MT-protein in vitro follows biphasic kinetics. Such kinetics were reported for bovine MT-protein (Barton \& Riazi, 1980) and have also been observed for both bovine and pig MT-protein (Bayley et al., 1983; Clark et al., 1984). [Biphasic kinetics are also illustrated by Kumar (1981) for glycerol-free bovine MT-protein.] By contrast, in the analysis of the assembly of pig MT-protein, only a single exponential process was resolved (Johnson \& Borisy, 1977; Engelborghs et al., 1977; Carlier, 1983). The numerical values for biphasic assembly (Table 1) show significant variation, even with a carefully controlled protocol. This necessitates performing a sufficiently large number of assembly experiments on successive identical preparations of MT-protein to establish the statistically defined limits. In addition to the demonstrated effects of buffer ion, $\mathrm{pH}$ and ionic strength, the nucleotide content, source and preparative procedure for the MT-protein affect these numerical values significantly. 

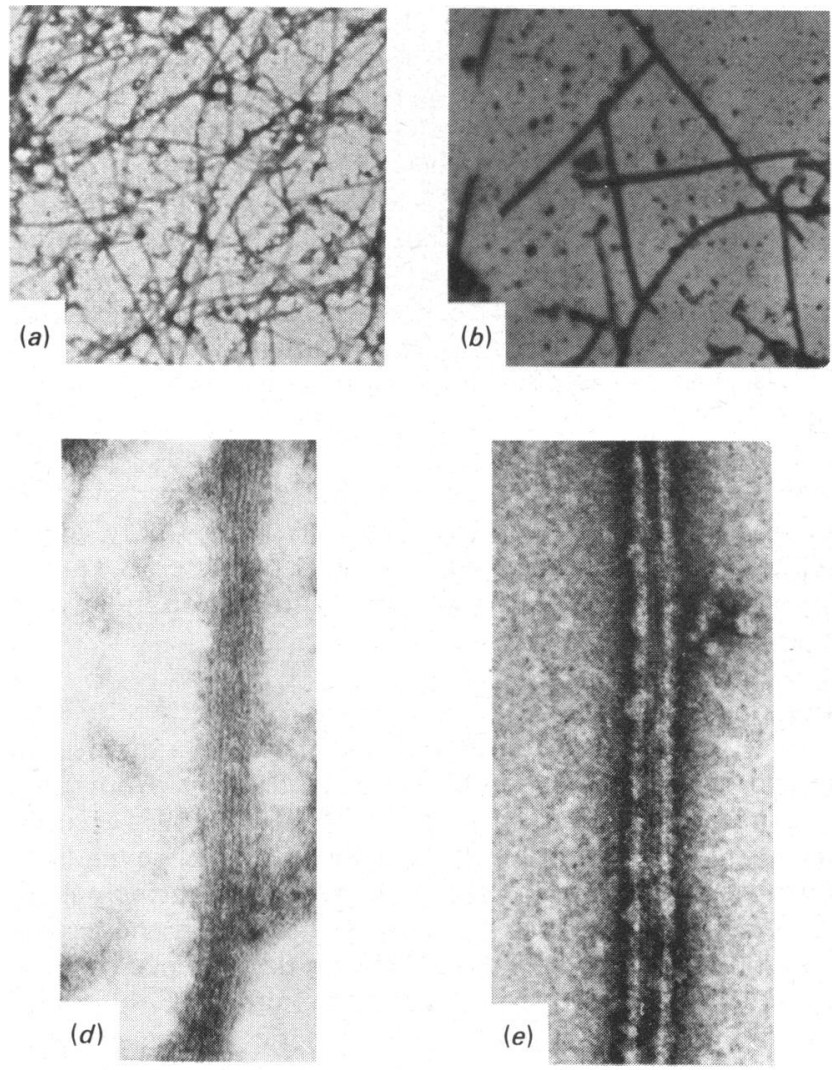
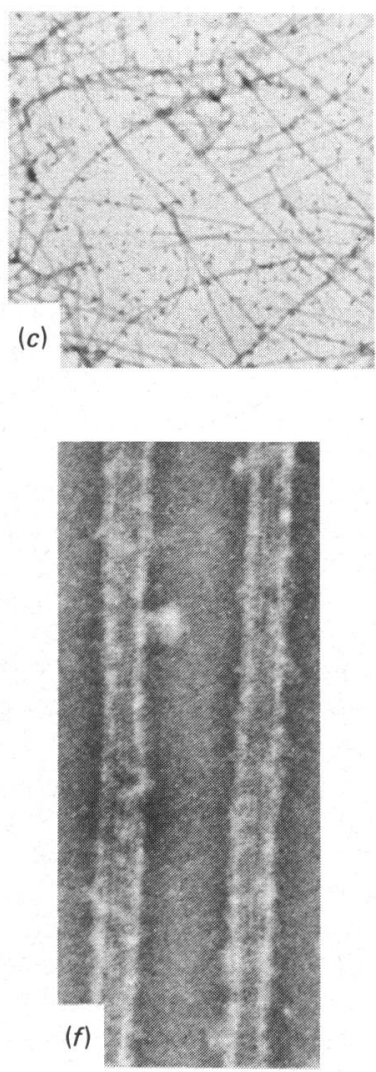
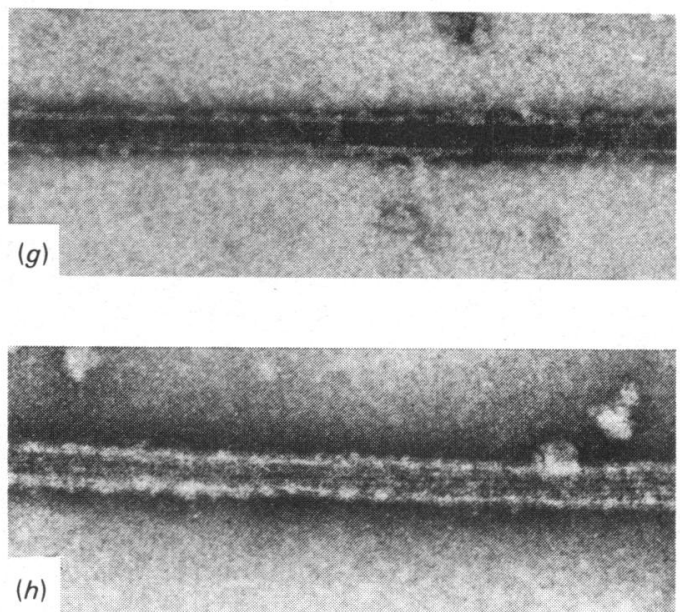

Fig. 8. Electron microscopy of assembling MT-protein, showing the continuous formation of rough-walled microtubules by negative staining ( $1 \%$ uranyl acetate) of unfixed material (a to g) or $1 \%$ glutaraldehyde-fixed material $(h)$ Assembly times: $(a)$ and $(d) 30 \mathrm{~s} ;(b)$ and $(e) 5 \mathrm{~min} ;(c)$ and $(f) 15 \mathrm{~min} ;(g)$ and $(h) 30 \mathrm{~min}$. Magnifications: $(a)-(c)$ $\times 12500 ;(d)-(h)(\mathrm{bar}=100 \mathrm{~nm}) \times 150000$.

With the use of a careful and consistent method of data acquisition and analysis, the kinetics are found to be biphasic throughout the range of conditions studied. Our treatment avoids any subjective estimate of plateau values $(t=\infty)$, which may easily be underestimated in the case of slow-phase kinetics. It also allows comparison of the quality of one-exponential and two-exponential 
fitting procedures applied over the major portion of the assembly curve. For pig MT-protein the fast phase is more sensitive to the higher $\mathrm{pH}$ range (e.g. Pipes buffer, pH6.9) than is the bovine MTprotein. The apparent single-phase kinetics observed by Johnson \& Borisy (1977) and Carlier (1983) (after adjustment for the temperaturedependence of the rate constants) correspond to the fast phase (Table 1). We note that these workers use different methods of analysis; the shorter data-collection period employed would render the slow phase more difficult to detect. Differences in preparative procedures, for example the possible depletion of MAPs in glycerolcycled pig MT-protein (Scheele \& Borisy, 1976), may contribute to differences in assembly behaviour. Further variation may be due to solution conditions, including GDP content, which is not always well-defined. The sensitivity of the fast phase to GDP implies an inhibition of early assembly intermediates in a manner analogous to that of microtubule elongation by GDP binding at the ends (Carlier \& Pantaloni, 1982).

The observation of multiphase kinetics is not restricted to turbidimetric results; the time course of low-angle X-ray scattering shows multiple phases, which have been correlated with the timedependent transformations of a number of species (Bordas et al., 1983). This work uses high concentrations of (pig) MT-protein, but the intramolecular processes would clearly persist under the conditions used in our experiments.

The kinetic turbidimetric results are relatively uninformative about those molecular processes operating during the lag phase that lead to the nucleation process preceding microtubule assembly. We see little effect of total initial protein concentration $\left(C_{0}\right)$ on the length of the lag phase, in contrast with the strong dependence required in the Oosawa condensation mechanism (where $t_{\frac{1}{t}}$, the time for $50 \%$ polymerization, is dependent on $\left(C_{0}\right)^{n / 2}$ for a nucleating species of $n$ molecules). The rate of nucleation is relatively slow and may be independent of protein concentration, owing either to the slowness of oligomer transformation (as above) in producing fragments that can form nuclei or to the slowness of fragment association or intramolecular isomerization in some prenucleating process. The concentration of nuclei is evidently not a high power of the protein concentration, since the number concentration of microtubules has been found to increase only linearly with $C_{0}$ (Engelborghs et al., 1977).

An important observation is the attainment of limiting values of $k_{\text {obs.1 }}$ and $k_{\text {obs.2 }}$ at higher total protein concentration, $C_{0}$ as reported by Clark et al. (1984) and supported by more extensive data here. [A limiting value of $15 \times 10^{-3}-20 \times 10^{-3} \mathrm{~s}^{-1}$ for $k_{\text {obs. }}$ at $30^{\circ} \mathrm{C}$ with $\mathrm{MT}$-protein concentration $6 \mathrm{mg} / \mathrm{ml}$ is also illustrated in Johnson \& Borisy (1977), Fig. 3(b).] At sufficiently high protein concentration, we find limiting values for both fast and slow processes over a range of conditions (Fig. 3 ). Thus a simple bimolecular addition is not ratedetermining. The likely mechanisms that give such behaviour are (a) isomerization and (b) dissociation. A slow intramolecular (isomerization) process in tubulin dimer was proposed as a ratedetermining step (Carlier, 1983), on the basis of the observation of a limiting value for the (singlephase) assembly rate of $0.2 \mathrm{~min}^{-1}$ for pig MTprotein assembled at $24^{\circ} \mathrm{C}$, and the deduction that the rate was not dependent on microtubule number concentration (as required by the Oosawa mechanism). However, no such isomerization has been demonstrated for the dimer by physical methods. Further, the rate does not obtain a limiting value in the seeded assembly of tubulin dimer (Johnson \& Borisy, 1977).

In considering a dissociation mechanism, Fig. 6(a) shows that the rate of dissociation of oligomeric species (under non-assembly conditions) is closely similar to the rate of the fast phase, both in its absolute value and in its temperature-dependence. The smallness of amplitude of the 'dip' preceding fast phase suggests either that only a small proportion of rings are dissociating, or alternatively that the rings undergo an isomerization or a dissociation process such as ring opening, to form alternative oligomers with only slightly diminished light-scattering properties (cf. Palmer et al., 1982). We find that the dissociation reaction is dependent on $\mathrm{pH}$, buffer ion and temperature (Martin et al., 1982), and under all conditions is of such amplitude that oligomeric material closely related to rings is still present in the early phase of assembly.

The report by Karr \& Purich (1980) that rings dissociate fully in the lag phase is not borne out by the present work. The earlier qualitative report that rings are not observed in electron microscopy during the early phase of assembly (Olmsted et al., 1974) may reflect the relative instability of oligomeric material subjected to assembly conditions before ultrastructural preparation. A substantial ring dissociation for pig MT-protein, on increasing the temperature above $20^{\circ} \mathrm{C}$, was observed by Pantaloni et al. (1981), by the use of analytical ultracentrifugation. Such measurements, in which no intermediate forms were observed, could overestimate ring lability because of the sensitivity of oligomeric forms to pressure (Scheele \& Borisy, 1979).

Thus there exists evidence for at least partial ring dissociation in the lag phase. The similarity in magnitude and temperature-dependence between $k_{\text {diss. }}$ and $k_{\text {obs. } 1}$ strongly argues that this oligomer 
dissociation process is the rate-determing step of the fast phase. The value of $k_{\text {diss. }}$ is also similar at $37^{\circ} \mathrm{C}$ to the estimated rate for an analogous process, namely dimer exchange into rings (Pantaloni et al., 1981), although the activation energy of the latter process is significantly lower. $k_{\text {diss. }}$ is such that fragments will be generated continuously throughout the fast phase of assembly; once nucleation has occurred (Mandelkow et al., 1982, 1985), elongation will proceed efficiently by addition of fragments at the growing end.

In considering the mechanism of the slow phase, which normally accounts for approx. $50 \%$ of total amplitude in the presence of $1 \mathrm{mM}-\mathrm{GTP}$ (Table 1), it is tempting to propose that this represents direct addition of free tubulin dimer. The Oosawa mechanism predicts that this addition would follow single-exponential kinetics with observed rate $k_{\mathrm{obs}}=k_{2}$ [end] for the process:

$$
\text { Dimer+end } \stackrel{k_{2}}{\rightleftharpoons} \text { end }
$$

Three points argue against this proposition. (1) The observed slow-phase rate $k_{\text {obs.2 }}$ also attains a limiting value with increasing protein concentration (see Figs. $3 b$ and $3 d$ ), a phenomenon not accounted for by the Oosawa mechanism, and not found in the seeded assembly of tubulin dimer (Johnson \& Borisy, 1977). (2) Elongation of a microtubule by addition of tubulin dimer to the growing end should be favoured thermodynamically only for dimer concentrations greater than $C_{\mathrm{c}}$, the critical concentration for pure dimer. In Mes buffers this is immeasurably high and is lowered to $1 \mathrm{mg} / \mathrm{ml}$ only by high concentrations of components such as glycerol, dimethyl sulphoxide or poly(ethylene glycol) (Lee \& Timasheff, 1975; Himes et al., 1977; Carlier \& Pantaloni, 1978; Herzog \& Weber, 1978). (3) At equilibrium, the end must include some MAP components, since the low critical concentration for MT-protein (0.1$0.2 \mathrm{mg} / \mathrm{ml}$ ) is absolutely dependent on the presence of MAPs, as observed by experiments with MTprotein, and with whole MAP fraction (or the purified fractions of MAP1, MAP2 or tau) reconstituted with purified tubulin dimer (Sandoval \& Vandekerckhove, 1981).

We therefore conclude that MAPs must also be involved in the mechanism of the slow phase. When MAP-rich microtubules are formed, MAP redistribution by dissociation or by intramolecular displacement could be a kinetically important pathway. The results of Figs. 7 and 8 suggest that the MAPs rapidly become associated with sedimentable microtubules. The critical point is the rate at which MAPs or MAP-containing fragments become available for slow additional assembly. MAPs are in dynamic equilibrium with assembled microtubules, and the half-life for exchange of MAPs with assembled microtubules (Manso-Martinez et al., 1980) is $10-20 \mathrm{~min}$ at $37^{\circ} \mathrm{C}$, corresponding to a rate constant of $1 \times 10^{-3}$ $2 \times 10^{-3} \mathrm{~s}^{-1}$. Thus the kinetics of MAP redistribution from assembled microtubules (and possibly from oligomeric fragments) appears to be of the correct order of magnitude to account for the limiting rate of the slow phase. We conclude that two processes, with rate constants $k_{\text {diss. }}$ (representing the dissociation of oligomers) and $k_{\mathrm{R}}$ (representing a redistribution reaction amongst MAPcontaining species), may play important kinetic roles in the mechanism of assembly of MT-protein.

\section{Role of MAP-containing fragments in assembly}

A general mechanism of assembly of MTprotein must explicitly consider the role of MAPs in the nucleation and elongation processes and account for $(a)$ biphasic kinetics in the elongation phase, $(b)$ limiting values for the rates $k_{\text {obs.1 }}, k_{\text {obs.2 }}$ at higher protein concentration $C_{0},(c)$ variation in kinetics with solution conditions, $(d)$ lag phase relatively insensitive to $C_{0}$, and $(e)$ a critical concentration at equilibrium typical of MTprotein. No single assembly model can account for these properties of the system, and further detailed evidence of the nucleation process is an essential prerequisite to constructing a truly general model for MT-protein assembly. However, we have derived a relatively simple working model, incorporating the processes $k_{\mathrm{diss}}$ and $k_{\mathrm{R}}$, that is able to account for many of the features of the assembly process. We assign a central role to MAPs (without differentiating between tau and MAP1 or MAP2 at this stage) and to the MAP-containing fragments deriving from the oligomers. These complexes may be characterized in terms of the parameter $r=$ MAPs/dimer, distinguishing those species rich in MAPs $\left(r_{\mathrm{A}}\right)$ and those depleted in MAPs $\left(r_{C}\right)$ relative to the steady-state ratio $\left(r_{\mathrm{B}}\right)$, which also characterizes the disassembled MTprotein. The absolute value of $r_{B}$ will depend on the preparative or recycling conditions and the source of protein (cf. Scheele \& Borisy, 1976). Since at pH 6.5 our MT-protein contains approx. $50 \%$ free dimer, it follows that $30 \mathrm{~S}$ ring oligomers are relatively rich in MAPs, with, on the average $r_{\mathrm{A}} \bumpeq 2 \times r_{\mathrm{B}}$.

The nucleation stage has been shown (Mandelkow et al., 1982;1983a,b) to involve dissociation of oligomeric rings into protofilament fragments from which derive the assembly-competent nuclei and (under the conditions of high protein concentration and slow temperature rise used for the kinetic X-ray-scattering experiments) an extensive population of 'kinetic overshoot complexes'. In the turbidimetric assay at much lower protein concen- 
tration and with a fast temperature jump, the concentration of the fragments that are the products of oligomeric ring dissociation will be determined by the balance of the kinetics of their formation and subsequent utilization.

The working model for assembly is shown in Scheme 1. Elongation occurs by addition of fragments to the nucleus, producing a growing microtubule with an end characterized by MT-A, MT-B or MT-C as MAP-rich, MAP-normal or MAPdepleted. The relative importance of the three pathways $\mathrm{A}, \mathrm{B}$ and $\mathrm{C}$ is determined by the nature and transient concentrations of the fragments produced by oligomer dissociation; $k_{\text {diss. }}$, being relatively slow, becomes the rate-limiting step for this phase of the elongation. In pathway $A$, addition of fragment A exclusively gives a microtubule with effectively all the MAPs incorporated; the preferential formation of a MAP-rich microtubule explicitly requires that the kinetics must be biphasic. The subsequent process requires the relaxation of the MAP-rich microtubule, by, for example, a rate-determining dissociation of MAPs $\left(k_{\mathrm{R}}\right)$, independent of protein concentration; the free MAPs would rapidly re-form fragments for subsequent incorporation. In pathway B, addition of fragment B exclusively gives microtubule elongation at a constant MAP/dimer ratio, with value $r_{B}$; this would give a single phase of assembly, again rate-limited by $k_{\text {diss. }}$. In pathway $\mathrm{C}$, addition

(1) Nucleation

Oligomer $\underset{k_{\text {diw. }}}{\longrightarrow}$ Fragments $\underbrace{\longrightarrow}_{\text {Elongation }}$ Nuclei $\longrightarrow \cdots$.

(2) Elongation

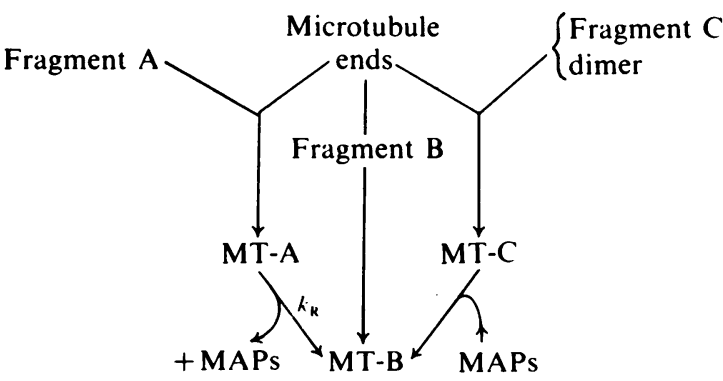

Scheme 1. Schematic model for microtubule assembly from $M T$-protein comprising (I) nucleation, i.e. formation from oligomeric fragments of the nuclei that then initiate the elongation (cf. Mandelkow et al., 1983b) and (2) elongation by addition of fragments to the growing microtubule ends Indices $A, B$ and $C$ represent species rich, average or depleted in MAPs (see the text). $k_{\text {diss. }}$ is the oligomer dissociation rate, and $k_{\mathrm{R}}$ the MAP redistribution rate. of dimer (or fragment $\mathrm{C}$ which in the limit $r_{\mathrm{C}} \rightarrow 0$ becomes dimer) corresponds to dimer assembly seeded by provision of nuclei (cf. Johnson \& 'Borisy, 1977), followed by the addition of free MAP to form a thermodynamically stable microtubule (Murphy et al., 1977). This implicates free MAPs as a reactant that does not affect the elongation rate, but that stabilizes the microtubule by decreasing the rate of depolymerization of tubulin dimer. However, this mechanism requires a substantial concentration of free MAPs, which has never been demonstrated experimentally.

The question of biphasic versus single-phase kinetics thus becomes the question of the relative magnitudes of $k_{\text {diss. }}$ and $k_{\mathrm{R}}$ under the particular solution conditions and the properties of the fragments A, B and C. Our results with bovine MT-protein have previously indicated a considerable stability of the oligomers. If ring dissociation yields fragment $A$ so that $2 r_{\mathrm{B}}>r_{\mathrm{A}}>r_{\mathrm{B}}$, then, with $k_{\text {diss. }}>k_{\mathrm{R}}$, an MAP-rich intermediate state (microtubules MT-A) must exist and biphasic assembly kinetics will be observed. If $k_{\mathrm{R}}$ is enhanced so that $k_{\text {diss. }} \sim k_{\mathrm{R}}$, or if oligomers yield higher proportions of fragment $B$, assembly will approach more closely to a single-phase process at limiting rate $k_{\text {diss. }}$ and with formation of microtubules showing a more nearly constant $r\left(=r_{\mathrm{B}}\right)$. Under conditions in which oligomers can undergo greater dissociation to dimers, mechanisms involving fragment $\mathrm{C}$ and dimer would be more important, but may still be affected by the value of $k_{\text {diss. }}$. Below that value, rates could show the dependence on dimer concentration characteristic of the Oosawa mechanism. Different solution conditions produce different distribution of fragment species and hence affect the subsequent kinetics, and it appears possible that fragments, like the growing microtubule ends, represent sites vulnerable to inhibition by GDP (cf. Carlier \& Pantaloni, 1982).

A decisive question is the nature of the material formed during fast-phase assembly. In pathway A most of the MAPs would be incorporated into a MAP-rich microtubule. By constrast, if appreciable concentrations of MAPs are sequestered in assembly-incompetent species, fast-phase elongation would produce microtubules with composition closer to $r_{\mathrm{B}}$. Stearns \& Brown (1979) showed that MAP2 is incorporated preferentially in the early stages of assembly, and consistent with this Pantaloni et al. (1981) deduced that the early phase of assembly at $22^{\circ} \mathrm{C}$ involves material deriving selectively from rings. The results of Fig. 7 argue strongly for the initial formation of MAP-rich microtubules. Sandoval \& Vandekerckhove (1981) showed that microtubules can become overloaded with MAP2 (or tau) during assembly and that both types of MAP can be displaced relatively easily 
from this state. The kinetics for exchange of MAP2 (Manso-Martinez et al., 1980) would constitute a rate-limiting step close to the limiting value of $k_{\text {obs.2. }}$. Thus the present evidence appears consistent with the slow dissociation of excess MAP from the growing microtubules being responsible for the concentration-independent kinetics of the slow phase of assembly.

This mechanism differs from that of Johnson \& Borisy (1977) and that of Carlier (1983) and from those general mechanisms for assembly of microtubule protein that involve tubulin dimer as the elongating species in a nucleated polymerization mechanism for assembly of microtubule protein. We emphasize that the concepts of the Oosawatype mechanism remain valid for assembly of pure tubulin dimer undergoing seeded tubulin assembly. However, in this case, the critical concentration must be that for tubulin dimer under the same solution conditions. The data of Fig. 5 show that the total amplitude of microtubule assembly at constant total protein concentration $(1 \mathrm{mg} / \mathrm{ml})$ decreases steadily with decreasing proportion of ring fraction, and a similar result has been obtained with dimer plus whole MAP fraction. Thus, even though nucleation occurs, the amount of assembly is proportional to the amount of MAP present, and the excess dimer is not assembled under these solution conditions.

The evidence presented here supports the view of Weisenberg (1980, Appendix) that elongation proceeds principally by addition of oligomeric fragments, and would also allow the possibility of 'filling-in' by tubulin dimer as a minor contributing mechanism. This mechanism also includes the propositions of Mandelkow et al. $(1982,1983 a, b)$ in that the fragments are closely related to protofilaments (cf. Bordas et al., 1983). These workers have observed extensive population of overshoot complexes, and, whereas this is a function of several solution variables, and not solely related to protein concentration (see Mandelkow et al., 1984), it appears less likely to predominate under our conditions of assembly after a temperature jump. Also, Scheme 1 stresses the potential heterogeneity of the fragments and the consequent heterogeneity of the growing microtubule end.

Thus this mechanism emphasizes the key role of MAPs in assembly of microtubule protein. As yet no distinctive function can be assigned to the two main components of the MAP fraction, although it appears from Sandoval \& Vandekerckhove (1981) that the assembly of tubulin dimer in the presence of either purified tau or purified MAP2 gives kinetics substantially different from the original MT-protein mixture. It is possible that different MAPs may act synergistically to produce species of differing morphology and stability that function distinctively in assembly, and Carlier et al. (1984) have inferred a functional polymorphism in oligomeric species, consistent with the properties of fragments $A, B$ and $C$ postulated in the present paper. The observations reported here suggest that complexes of tubulin dimer plus MAPs are kinetically important intermediates at all stages of the assembly, and that these complexes are derived from those equilibrium oligomeric species observed in cold-dissociated MT-protein. The mechanism implies a strong correlation between biphasic kinetics and the initial formation of MAP-rich microtubules. The relative importance of the different pathways in Scheme 1 can be assessed experimentally by detailed examination of the MAP content of the product of the fast phase of MT-protein self-assembly. Conditions favouring biphasic kinetics should show formation of microtubules with more constant MAP/tubulin ratio. This mechanism also emphasizes the lability of MAP-tubulin interactions, a property of potential biological importance in the cytoskeletal function of the microtubule system.

D. C. C. acknowledges the support of a Medical Research Council Training Fellowship. We thank Dr. M. Nermut for helpful advice. We are grateful to Mrs. A. Humphrey-Gaskin for assistance in preparing this manuscript.

\section{References}

Barton, J. S. \& Riazi, G. H. (1980) Biochim. Biophys. Acta 630, 392-401

Barton, J. S. \& Riazi, G. H. (1982) Biochim. Biophys. Acta 705, 8-11

Bayley, P. M., Charlwood, P. A., Clark, D. C. \& Martin, S. R. (1982) Eur. J. Biochem. 121, 579-585

Bayley, P. M., Clark, D. C. \& Martin, S. R. (1983) Biopolymers 22, 87-91

Berne, B. J. (1974) J. Mol. Biol. 89, 756-758

Bordas, J., Mandelkow, E.-M. \& Mandelkow, E. (1983) J. Mol. Biol. 164, 89-135

Borisy, G. G., Marcum, J. M., Olmsted, J. B., Murphy, D. B. \& Johnson, K. A. (1975) Ann. N.Y. Acad. Sci. 253, 107-132

Camerini-Otero, R. D. \& Day, L. A. (1978) Biopolymers 17, 2241-2249

Carlier, M.-F. (1983) J. Biol. Chem. 258, 2415-2420

Carlier, M.-F. \& Pantaloni, D. (1978) Biochemistry 17, 1908-1915

Carlier, M.-F. \& Pantaloni, D. (1982) Biochemistry 21, 1215-1224

Carlier, M.-F., Simon, C. \& Pantaloni, D. (1984) Biochemistry 23, 1582-1590

Clark, D. C., Martin, S. R. \& Bayley, P. M. (1981) Biochemistry 20, 1924-1932

Clark, D. C., Martin, S. R. \& Bayley, P. M. (1984) J. Submicrosc. Cytol. 16, 27-28 
Correia, J. J. \& Williams, R. C. (1983) Annu. Rev. Biophys. Bioeng. 12, 211-235

Detrich, H. W. \& Wilson, L. (1983) Biochemistry 22, 2453-2462

Dhalla, S. S., Sharma, R. K. \& Wang, J. H. (1981) FEBS Lett. 134, 257-260

Engelborghs, Y., De Maeyer, L. C. M. \& Overbergh, N. (1977) FEBS Lett. 80, 81-85

Erickson, H. P. (1974) J. Supramol. Struct. 2, 393-411

Gaskin, F., Cantor, C. R. \& Shelanski, M. L. (1974) J. Mol. Biol. 89, 737-759

Herzog, W. \& Weber, K. (1978) Eur. J. Biochem. 91, 249254

Himes, R. H., Burton, P. R. \& Gaito, J. M. (1977) J. Biol. Chem. 252, 6222-6228

Johnson, K. A. \& Borisy, G. G. (1977) J. Mol. Biol. 117, 1-31

Karr, T. L. \& Purich, D. L. (1980) Biochem. Biophys. Res. Commun. 95, 1885-1889

Keates, R. A. B. (1980) Biochem. Biophys. Res. Commun. 97, 1163-1169

Kirschner, M. W. (1978) Int. Rev. Cytol. 54, 1-71

Krauhs, E., Little, M., Kempf, T., Hofer-Warbinek, R., Ade, W. \& Ponstingl, H. (1981) Proc. Natl. Acad. Sci. U.S.A. 78, 4156-4160

Kumar, N. (1981) J. Biol. Chem. 256, 10435-10441

Lee, J. C. \& Timasheff, S. N. (1975) Biochemistry 14, 5183-5187

Mandelkow, E., Mandelkow, E.-M. \& Bordas, J. (1983a) J. Mol. Biol. 167, 179-196

Mandelkow, E, Mandelkow, E.-M. \& Bordas, J. (1983b) Trends Biochem. Sci. 8, 374-377

Mandelkow, E., Schultheiss, R. \& Mandelkow, E.-M. (1984) J. Mol. Biol. 177, 507-529

Mandelkow, E., Mandelkow, E.-M., Renner, W. \& Bordas, J. (1985) in Spectroscopy and the Dynamics of Molecular Biological Systems (Bayley, P. M. \& Dale, R. E., eds.), Academic Press, London, in the press

Mandelkow, E.-M., Harmsen, A., Mandelkow, E. \& Bordas, J. (1980) Nature (London) 287, 595-599

Mandelkow, E.-M., Bordas, J. \& Mandelkow, E. (1982) Biol. Cell 45, 425

Manso-Martinez, R., Villasante, A. \& Avila, J. (1980) Eur. J. Biochem. 105, 307-313

Marcum, J. M. \& Borisy, G. G. (1978) J. Biol. Chem. 253, 2825-2833
Martin, S. R., Clark, D. C. \& Bayley, P. M. (1982) Biochem. J. 203, 643-652

Murphy, D. B., Johnson, K. A. \& Borisy, G. G. (1977) J. Mol. Biol. 117, 33-52

Olmsted, J. B. \& Borisy, G. G. (1975) Biochemistry 14, 2996-3005

Olmsted, J. B., Marcum, J. M., Johnson, K. A., Allen, C. \& Borisy, G. G. (1974) J. Supramol. Struct. 2, 429-450

Oosawa, F. \& Asakura, S. (1975) Thermodynamics of the Polymerisation of Protein, Academic Press, London

Palmer, G. R., Clark, D. C., Bayley, P. M. \& Sattelle, D. B. (1982) J. Mol. Biol. 160, 641-657

Pantaloni, D., Carlier, M.-F., Simon, C. \& Batelier, G. (1981) Biochemistry 20, 4709-4716

Ponstingl, H., Krauhs, E., Little, M. \& Kempf, T. (1981) Proc. Natl. Acad. Sci. U.S.A. 78, 2757-2761

Sandoval, I. V. \& Vandekerckhove, J. S. (1981) J. Biol. Chem. 255, 8795-8800

Sandoval, I. V. \& Weber, K. (1980) J. Biol. Chem. 255, 8952-8954

Sato, H., Kato, T., Takahashi, T. C. \& Ito, T. (1982) in Biological Functions of Microtubules and Related Structures (Sakai, H., Mohri, H. \& Borisy, G. G., eds.), pp. 211-226, Academic Press, Tokyo

Scheele, R. B. \& Borisy, G. G. (1976) Biochem. Biophys. Res. Commun. 70, 1-7

Scheele, R. B. \& Borisy, G. G. (1979) in Microtubules (Roberts, K. \& Hyams, J. S., eds.), pp. 175-254, Academic Press, New York

Shelanski, M. L., Gaskin, F. \& Cantor, C. R. (1973) Proc. Natl. Acad. Sci. U.S.A. 70, 765-768

Stearns, M. E. \& Brown, D. L. (1979) FEBS Lett. 101, 15-20

Timasheff, S. N. (1981) in Molecular Approaches to Gene Expression and Protein Structure (Siddiqui, M. A. Q., Krauskopf, M. \& Weissbach, H., eds.), pp. 245-285, Academic Press, New York

Timasheff, S. N. \& Grisham, L. M. (1980) Annu. Rev. Biochem. 49, 565-591

Weisenberg, R. C. (1980) J. Mol. Biol. (Appendix) 139, 660-677

Williams, R. C. \& Detrich, H. W. (1979) Biochemistry 18, 2499-2503

Woody, R. W., Clark, D. C., Roberts, G. C. K., Martin, S. R. \& Bayley, P. M. (1983) Biochemistry 22, 21862192 